\title{
Dual Axis Solar Tracker with Weather Sensor
}

\author{
T.M. Thamizh Thentral, Meghna Kannan, V Sai Mounika, Mahima Nair
}

\begin{abstract}
This paper presents the outline and execution of simple, easy and cheaper automatic dual axis solar tracking system using Arduino UNO as the control element and light detecting sensors (LDRS) as the sensing element. This project involves advanced level of technology to capture maximum amount of energy using sun's radiations. The main purpose is to increase the efficiency of tracking system which can rotate in all four directions continuously according to intensity of radiations and for energy conversion. In this, the voltage from panel is calculated from time to time in an interval of $1 \mathrm{hr}$ and this voltage is used to sense the weather conditions and display the climatic temperatures.
\end{abstract}

KEYWORDS: Solar panel, Arduino UNO, Light detecting resistors (LDRs), servo motors, temperature sensors, humidity sensors, rain drop sensors.

\section{INTRODUCTION}

The demand for reliable and abundant source of energy has been increasing day by day [1]. So, government improved the usage of renewable energy sources there by curtailing the usage of conventional source of energy. Sun is the most valued source of renewable energy. By using photovoltaic cell we can harness solar energy and later photovoltaic effect can be used to convert solar energy into electrical energy and this energy can be used in wide applications like solar thermal energy, solar heating, photovoltaic, solar architecture etc......[2]. The output of photovoltaic cell directly depends on the intensity of light and sun's positions changes continuously in a day. As sun is a major source of this renewable energy, a dual axis solar tracker which can track the radiations from the sun in all the directions with maximum intensity is found. [5]This dual axis solar tracker takes the sun radiations as the input and converts to electrical energy this electrical energy which is obtained fulfil majority of the country needs.[3] Energy absorption is maximum when the panel is perpendicular to the sun. Hence we are using a solar tracker to maximize the energy generation and improve the efficiency $40 \%$ more than the fixed panel. In general, during the day the single axis tracker moves from east to west with one degree of freedom. While the modern tracker tracks east west and north south movement of the sun. In this project we are integrating dual axis solar tracking

Revised Version Manuscript Received on 10, September 2019.

T.M. Thamizh Thentral, Assistant Professor, Department of Electrical and Electronics Engineering, SRM Institute of Science and Technology, Chennai, Tamilnadu, India (Email: thentral2kuna@gmail.com)

Meghna Kannan, Student, Department of Electrical and Electronics Engineering, SRM Institute of Science and Technology, Chennai, Tamilnadu, India.

V Sai Mounika, Student, Department of Electrical and Electronics Engineering, SRM Institute of Science and Technology, Chennai, Tamilnadu, India.

Mahima Nair, Student, Department of Electrical and Electronics Engineering, SRM Institute of Science and Technology, Chennai, Tamilnadu, India. system with weather sensor. [7] It detects temperature, raindrop and humidity by using sensors and the output of these sensors can be seen in liquid crystal display(LCD).Light detecting resistors(LDR's) which can sense the maximum intensity of light and the arduino which guides the rotation of servomotors towards the maximum intensity of light is used. Servomotors are used to rotate the solar panel. Sensors are used to sense the weather conditions. [2]

From the past million years man has needed and used Energy at an increasing rate for his existence and well-being. Solar energy promises of becoming reliable energy source without any polluting effects. Hence obtaining of maximum energy with this method is more efficient and beneficial. [1]

\section{METHODOLOGY}

The entire set up is divided into 3 parts the light detecting unit, monitoring unit and the movement controlling unit. [1]

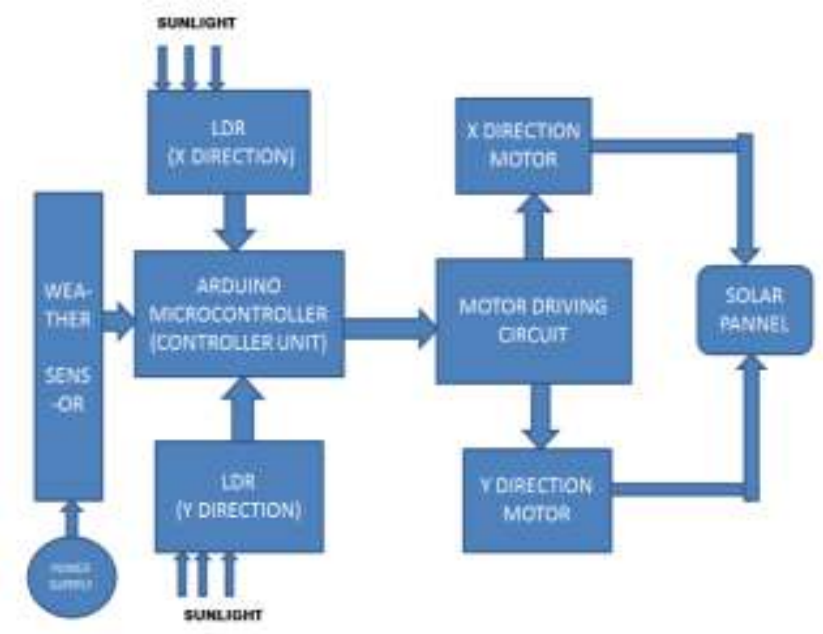

Figure .1 BLOCK DIAGRAM

\subsection{LIGHT DETECTING UNIT}

It consists of four light detecting resistors each forming a pair of two. It measures the light intensity and converts it into analog voltage and gives the input to the controller. One pair of LDR trace the location of sun in east- west direction and the other pair senses in the north-south direction. Resistance is inversely proportional to intensity of light and hence it decreases with increase in light intensity. The relationship between light intensity and resistance is given in the equation $\mathrm{R}_{\mathrm{L}}=500 / \mathrm{LUX}$ 


\subsection{MONITORING UNIT}

Arduino is the main monitoring unit of the entire apparatus as showed in fig.1..LDR is connected to the first four pins of Arduino i.e. $\mathrm{A}_{0-} \mathrm{A}_{4}$. Arduino takes the input from the LDR and based on that it gives instructions to servomotors to rotate either in horizontal or vertical directions.

\subsection{MOVEMENT CONTROLLING UNIT}

The movement controlling unit comprises of two servo motors. The Arduino gives an output of $5 \mathrm{v}$ which is used to drive the servo motor which can be driven by an input of about 4.5 volts. One of the motor controls the horizontal rotation while the other controls the vertical rotation. Only one motor functions at a time so as to reduce the power consumption.

\subsection{WEATHER SENSOR}

It comprise of a weather sensing unit in which arduino is used as an interfacing device and indicates the surrounding temperature conditions and humidity which is displayed on LCD display device.

\section{THE EXPERMIENT}

In the dual axis solar tracking system the solar panel which is fixed on a structure rotates based on the position of the sun which is sensed by the sensor.

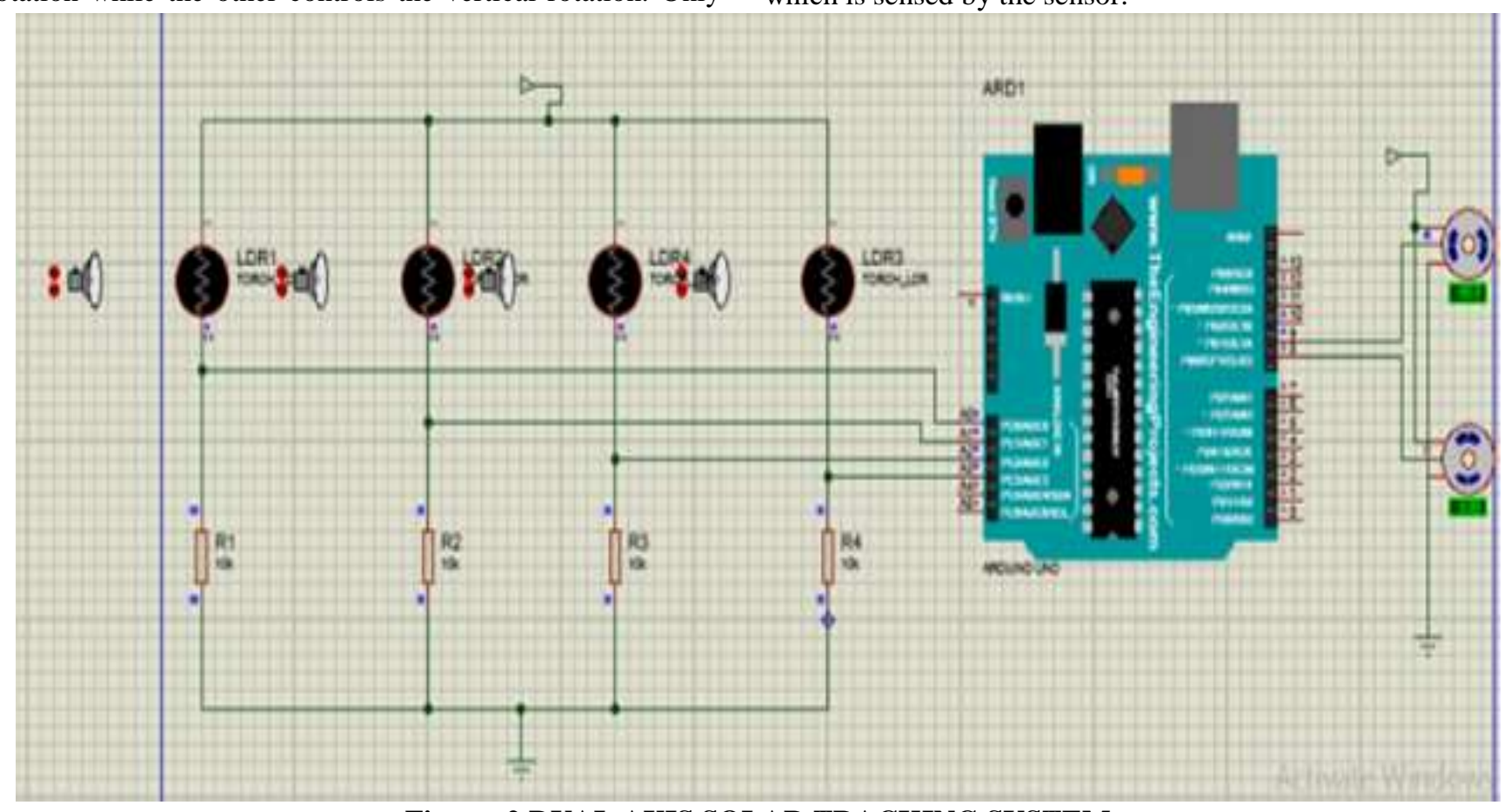

Figure. 2 DUAL AXIS SOLAR TRACKING SYSTEM

Four analog pins of arduino i.e. A1, A2, A3, A4 are connected to four resistors and four LDR's respectively which are internally connected in a voltage divider pattern as shown in fig 3.The two servo motor gets PWM inputs from digital pins 9 and 10 of Arduino as shown in fig .3.LDR's serves as the main light sensors. Servo motor is supported by two solar panels which are fixed to the structure. Arduino program is uploaded to the microcontroller. The performance of the model is as follows:-When sun light falls on LDR, it senses the amount of sunlight falling on it and each LDR senses in top, bottom, left, right directions respectively. For north-south tracking, the analog values from two top LDR's and two bottom LDR's are compared and if the bottom set of LDR's receive more light, the vertical servo will move in that direction. If more light is sensed by top LDR's then the servo motor moves in that direction. The analog values from two left LDRs and two right LDRs are compared for angular deflection. If the right set of LDRs receives more light than the right set, the horizontal servo will move in that direction.

- $\quad$ Take a pcb board. Fix the solar panel in the center of the PCB with the help of glue.

- Mark the points for 4 LDRs to the four corners of the solar panel and bring the two wires of the panel to check the output.
- Now cut one of the two leads of the LDR so that one lead is shorter and other is longer to indicate the polarities, which will be easier while soldering.

- Insert these four LDRs into to the marked points in the PCB.

- $\quad$ Bend the perforated metal strips (aluminum) into the respective shapes as shown in the figure.

- $\quad$ Place one of the bent metal strip on the back side of the pcb with the help of glue.

- Solder the two leads of the LDRs as in the circuit.

- To the other ends of the LDR's leads solder resistors of $10 \mathrm{k} \Omega$.

- $\quad$ Connect the four leads of the 4 LDRs by connecting wires.

- Now with the help of bus wires connect them to the LDRs to get the output from them. Give the output to the Arduino board to the respective pins.

- Insert it into the perforated metal strip as shown in the figure.

- Now solder the connecting wires as per the circuit as well as to the resistors. 
- Insert another two wires through the perforated metal strip to give the supply of VCC and GND.

- Solder one of the wires to the one side of the LDR and the resistors and other wire is soldered to the other side.

- Short the leads of the LDR with wires to the resistors.

- $\quad$ Now fix a servo motor to the metal strip with help of glue and screw. Connect them to the arduino board to the respective pins.
- Now take another perforated metal strip (aluminium) which is bent in the respective shape as shown in the figure.

- $\quad$ Now to this metal strip fix another servo motor with the help of screw and glue. Now your solar tracker setup is ready.

\section{WEATHER SENSOR}

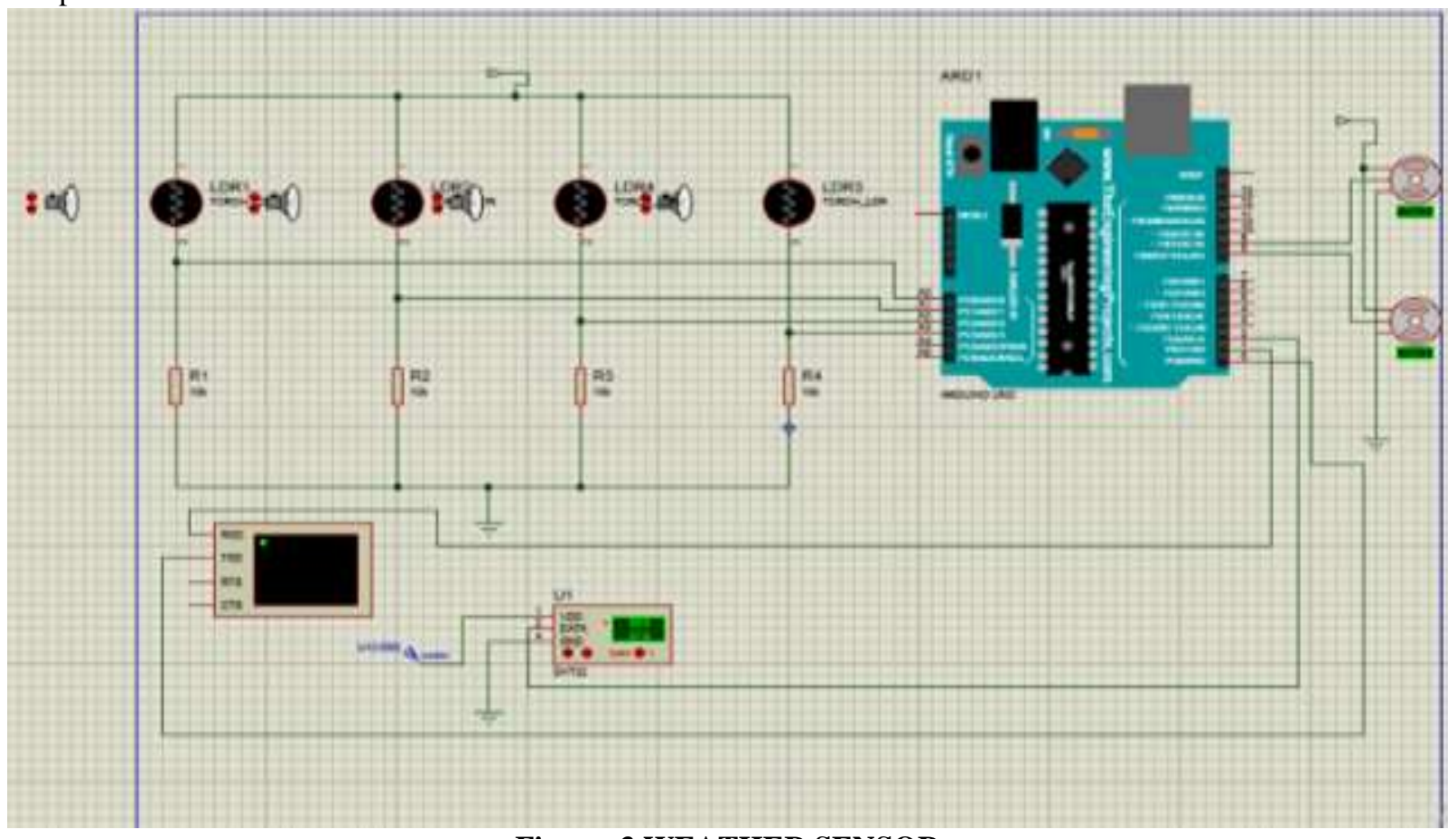

Figure .3 WEATHER SENSOR

- Initially the $16^{*} 2 \mathrm{LCD}$ display is connected to $\mathrm{i} 2 \mathrm{c}$ module.

- Then the Vcc pin is connected to 5 volts supply of arduino and the ground of i2c module is connected to the ground of arduino as shown in fig 4.

- The DHT11 senor's pins i.e. ground, Vcc, signal is connected to the Arduino.

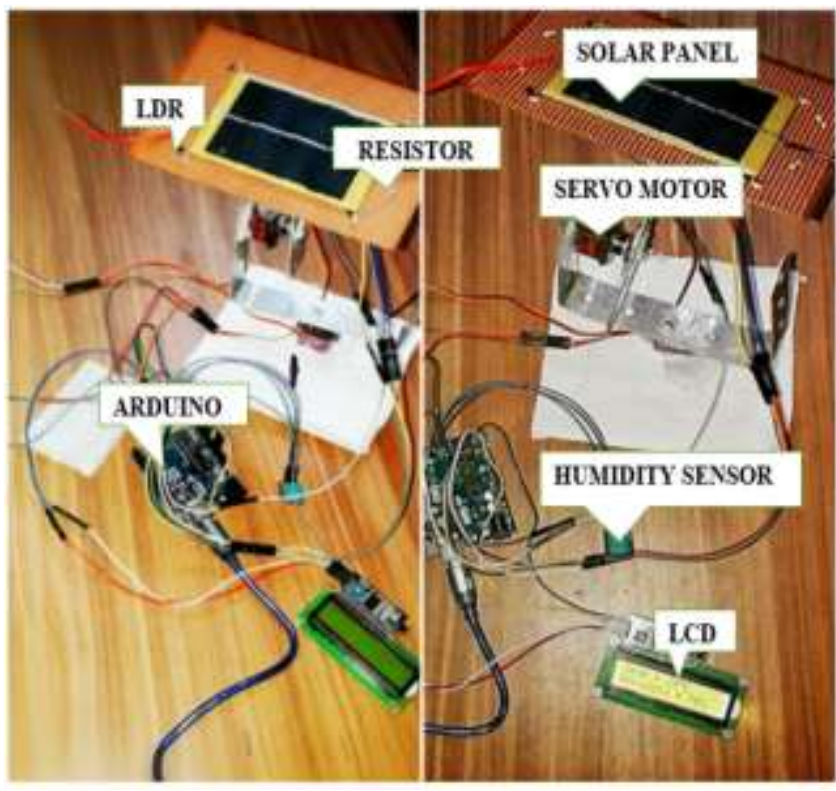

Figure .4 MODEL
IV. RESULT

Thus, Experiment outcomes of the system were performed by placing it in the rooftop (refer fig .5). This output voltage is collected from 8:00 AM to 6:00PM.

Output of dual axis solar tracker-

\section{Table.1 OBSERVATION OF SOLAR TRACKER}

\begin{tabular}{|c|c|c|}
\hline TIMI $(\mathrm{Hr})$ & SINGLE AXIS & DUAL AXIS \\
\hline $8: 00$ & 04.62 & 07.18 \\
\hline $9: 00$ & 06.4 & 10.11 \\
\hline $10: 00$ & 07.15 & 13.98 \\
\hline $11: 00$ & 09.23 & 15.72 \\
\hline $12: 00$ & 10.41 & 19.26 \\
\hline $13: 00$ & 13.77 & 19.78 \\
\hline $14: 00$ & 14.89 & 17.45 \\
\hline $15: 00$ & 15.56 & 16.89 \\
\hline $16: 00$ & 15.12 & 16.21 \\
\hline $17: 00$ & 13.45 & 12.47 \\
\hline $18: 00$ & 05.73 & 06.86 \\
\hline
\end{tabular}




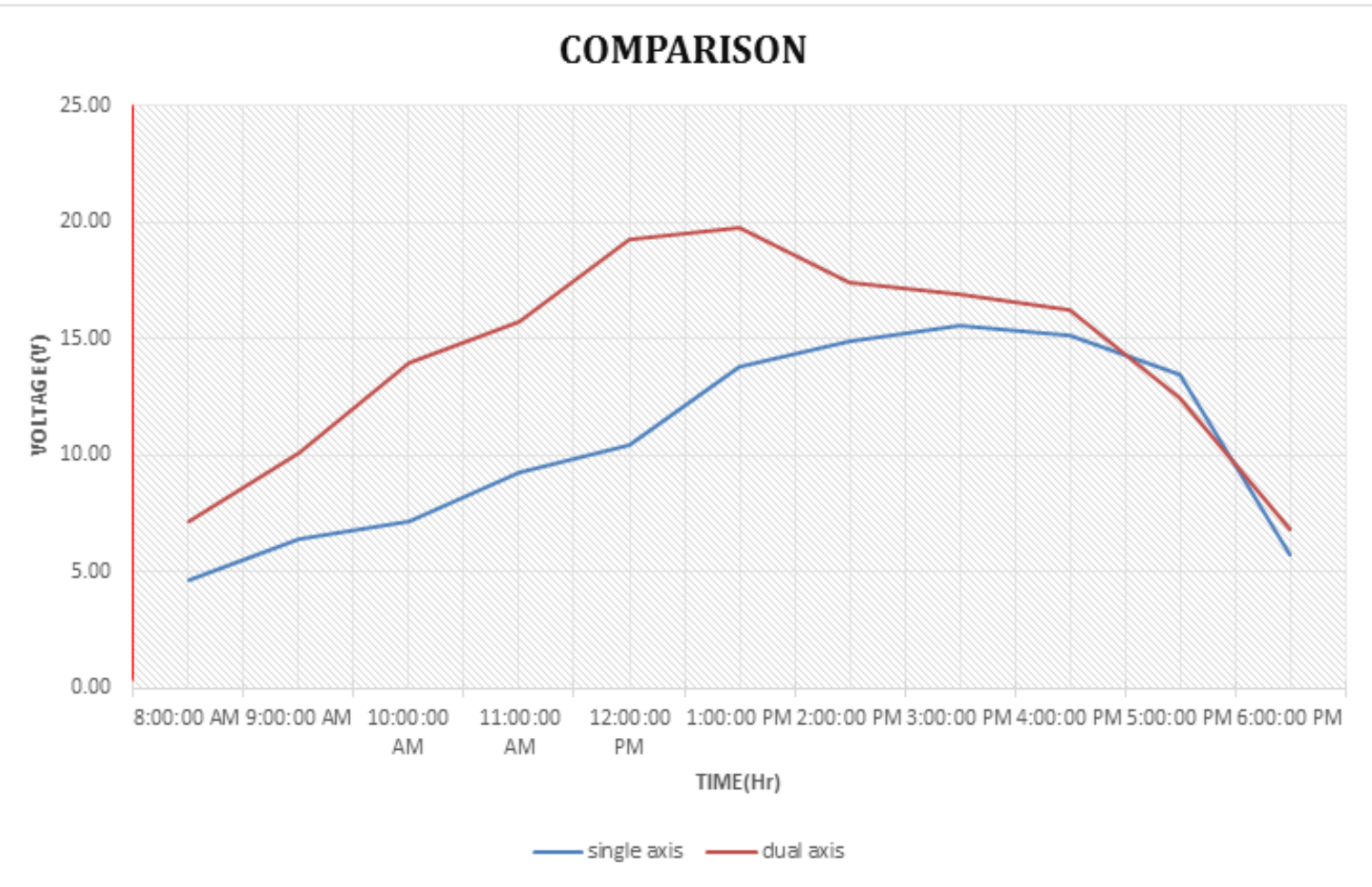

Figure. 5 GRAPH

The table which is shown above indicates the output values at different time intervals. As we know dual axis solar tracker is more productive than single axis solar tracker, comparison of output voltages of both the tracking methods is done.

Output of weather sensor-

Table. 2 OBSERVATION OF WEATHER SENSOR

\begin{tabular}{|l|l|l|}
\hline TIMIE(Hour) & TEMIPERATURE $\left({ }^{\circ} \mathrm{C}\right)$ & $\begin{array}{l}\text { HUMIITY } \\
(\%)\end{array}$ \\
\hline $16: 00$ & 33 & 65 \\
\hline $19: 00$ & 29 & 78 \\
\hline
\end{tabular}

The graphical representation is also seen in the graph mentioned above. Dual axis solar tracker system has high voltage capturing capacity. Graphical representation is undoubtedly showing the improved solar energy conversion when compared to other systems. Other than this there are some other techniques used for efficient tracking of solar radiations such as power towers, parabolic dish concentrator, parabolic trough concentrator, central receiver concentrator etc. but all these are very expensive. So, as dual axis solar system is less expensive, highly efficient it is used more common.

\section{CONCLUSION}

Dual axis solar tracker is placed in order to track the suns radiations in all the directions with maximum intensity to produce electricity. It is the most efficient method for the energy conversion and less economical when compared to other systems. This paper shows us the comparison of single axis solar tracker with dual axis solar tracker where it is clearly shown that dual axis is more efficient (refer fig.6) and produces more than $40 \%$ of the energy when compared to fixed and single axis solar tracking system.

\section{REFERNCES}

1 Falah I. Mustafa ; Sarmid Shakir ; Faiz F. Mustafa ; Athmar Thamer Naiyf2018 9th International Renewable Energy Congress (IREC)

2 T. Zhan, W. Lin, M. Tsai, G. Wang, "Design and Implementation of the Dual-axis Solar Tracking System IEEE", 37th Annual Computer Software and Applications Conference, pp. 276-277, 2011.

3 M. Zolkapli, S. A. AI-Junid, Z. Othman, A. Manut, Mohd Zulkifli, "IEEE", International Conference on Technology Informatics Management Engineering \& Environment, pp. 43-47, 2013

4 Nabee1 Abid Al-Sahib, Fa1ah I. Mustafa, Ayad M. Kwad, The Fourth International Renewable Energy Congress, December 20-22, 2012.

5 Falah Mustafa, Abd Salam Al-Ammri, Farouk Ahmad, The eighth International Renewable Energy Congress (IREC 2017), March 21-23, 2017.

6 Soumen Ghosh, Nilotpal Haldar, International Journal of eme Technology and Advanced Engineering, vol. 4, no. 12, December 2014.

7 Hussain S. Akbar, Abulrahman Siddiq, Marwa W. Aziz, American Journal of Energy Research, vol. 5, no. 1, pp. 23-27, 2017.

8 K Deekshith, Dhruva Aravind, H Nagaraju, Bhaskar Reddy International Journal of Scientific \& Engineering Research, vol. 6, no. 9, September 2015.

9 F.A. Hunter, B.P. Dougherty, M.W. Davis, "Measured performance of building integrated photovoltaic panels", Proc. Solar energy: the power to choose, 2001.

10 M.V. Kitaeva, A.V. Yurchenko, A.V. Skorohodov, A.V. Okhorzina, "Solar tracker", Siberian Journal of Science, vol. 4, no. 3, 2012. 